\title{
The role of disability $\&$ accessibility in corporate sustainability reporting
}

\begin{abstract}
Although companies increasingly focus on the social dimension in corporate sustainability, there seems to be a lack of understanding how and to what extent disability \& accessibility (D\&A) frameworks and activities are integrated in corporate sustainability reports. In this article, we aim to close this gap by a) analyzing the disability \& accessibility activities from the largest 50 companies in Europe based on their corporate sustainability reports, and b) advancing a simplified conceptual framework for D\&A that can be used in corporate reporting. In particular, we provide an overview about corporate D\&A reporting and associated activities according to three identified areas: a) workforce, b) workplace, and c) products and services. Our findings are twofold: First, the majority of the companies address disability \& accessibility in their corporate sustainability reports mainly under the diversity umbrella, but lack a detailed debate about the three identified areas. Second, we found that existing frameworks for D\&A are hardly used because either they are not focused on corporate reporting or seem too difficult or complicated to complete. Thus, our framework not only represents a first opportunity to foster the implementation of a D\&A framework within the social dimension of corporate sustainability reports, but also presents a holistic yet flexible management tool that takes into account the most critical elements while shaping implementation, directing evaluation and encouraging future planning of D\&A initiatives. As such, this study contributes to and extends the limited amount of research of D\&A activities in the social dimension in corporate sustainability reporting.
\end{abstract}

\section{Introduction}

As a response to a higher global public awareness and sensitivity to the contributing role that business organizations play in ecological, social and economic problems, there is a growing readiness for the world's largest companies to demonstrate their commitment to corporate sustainability. In this context, increasing numbers of organizations appear willing to report their economic, social and ecological sustainability performance and this is further supported by the growth in reporting standards such as the global reporting initiative (GRI) (Maas, Schaltegger, \& Crutzen, 2016). As a consequence, more than three quarters of companies issue sustainability reports and have expanded their reporting e.g. by linking their activities to the United Nations (UN) Sustainable Development Goals (SDGs) or acknowledging human rights as a business issue (KPMG, 2017). Moreover, while former sustainability reports have focused more on the ecological or environmental dimension of sustainability, a shift towards the social dimension in corporate reporting can be observed (Missimer, Robèrt, \& Broman, 2017).

However, while a rigorous debate has developed around the concept of environmental sustainability, its definition, indicators and measurements and its application and realization (McKenzie, 2004), scholars found that the situation is much less clear concerning social sustainability and is still receiving less recognition in comparison to the economic and environmental aspects (Vallance, Perkins, \& Dixon, 2011). In particular, although the social 
dimension has been increasingly incorporated in corporate sustainability reporting, it seems that the 'disability and accessibility' (D\&A hereafter) aspect in corporate sustainability reporting has largely been neglected.

In this article, we argue that the D\&A aspect is not only under-researched from an academic perspective, but also under-represented from corporate reporting viewpoint. In fact, despite the crucial importance of D\&A in the context of the social dimension in corporate sustainability reporting, the latest research articles as well as corporate reports on the social dimension often lack not only any form of systematic or adequate discussion on this topic, but are also fail to present consolidated and generally accepted frameworks (KPMG, 2017). This is somewhat surprising, given that almost 15 per cent of the world's population live with some type of disability (Nations, 2016; WHO, 2011) and thus represent a significant amount of the global workforce (Amla, 2008). In an attempt to address this gap, we present a simplified and comprehensively designed D\&A management framework (DAMF) that not only helps to better understand and categorize D\&A activities and disseminate the knowledge between academics and managers, but also provide a practical conceptual foundation for practitioners in the field of corporate sustainability reporting as well as academics in advancing state-of-art reporting and scholarship in this crucial space.

As the D\&A aspect can be regarded as a reporting element in its infancy, an examination of the current state of D\&A reporting in the latest existing corporate sustainability reports from the 50 largest companies in Europe would provide a good opportunity to categorize and synthesize the existing literature. Thus, the aim of this paper is threefold. First, we propose a new simplified DAMF framework from a corporate point of view with a focus on the social dimension that can be used in a corporate sustainability reporting context. Second, we examine and analyse the corporate sustainability reports of the largest 100 companies in Europe according to the D\&A activities for three identified areas workforce, workplace and product \& services. Third, we use the findings to highlight gaps and future research directions that can prompt further debate and investigation into this important yet neglected field of study.

The remaining paper is structured as follows: In the next section, the scope and characteristics of D\&A are identified, and key elements of the proposed DAMF are outlined. This is followed by the description of the methodology used to perform our analysis of the corporate sustainability reports of the 50 largest companies in Europe. Next, the main findings from the analysis are presented, followed by a discussion about the current state of D\&A activities of the companies with regard to workforce, workplace and product \& services. Finally, a research agenda is proposed which is built on current gaps in the literature and provide directions for future research.

\section{Scope and characteristics of Disability \& Accessibility (D\&A) Management}

Corporate social responsibility (CSR) and corporate sustainability are increasingly of strategic importance for business and corporations (Babiak \& Trendafilova, 2011; Lee, Herold, \& Yu, 2016). While CSR and corporate sustainability are similar concepts and both include three dimensions, namely social, environmental and economic, corporate sustainability can be regarded as more substantial concept (Baumgartner, 2014; Breitbarth \& Herold, 2018; Van Marrewijk, 2003) where businesses focus on contributions to the 'sustainable development' 
(see Brundtland, 1987) by implementing sustainable practices in a corporate context (Gray, 2006; Herold, Farr-Wharton, Lee, \& Groschopf, 2018; Herold \& Lee, 2019; Herremans, Nazari, \& Mahmoudian, 2016; Kolk, 2003; Milne \& Gray, 2013). To communicate those practices, companies disclose information about their social and environmental dimensions in form of corporate sustainability reports.

But although the social dimension in corporate sustainability reporting is of increasing importance for business, it has so far received less attention than the ecological dimension (Griessler \& Littig, 2005). In fact, the social dimension of sustainability can also be regarded as the least developed dimension of sustainability (Cuthill, 2010; Dempsey, Bramley, Power, \& Brown, 2011; Kunz, 2006) and recent scholars have shown the need for further development of the social dimension (e.g. Eizenberg \& Jabareen, 2017; Missimer, 2013; Wolbring \& Rybchinski, 2013). This lack of reporting is particular true for the D\&A aspect of the social dimension (see Cordero, de Zúñiga, \& Rueda, 2014), despite its high relevance for the workforce (Vallance et al., 2011; Wolbring, Mackay, Rybchinski, \& Noga, 2013) and its specific reference in the United Nations Sustainability Development Goals (UN SDGs).

Although D\&A is mentioned in six SDGs, corporate reporting is mainly linked to three SDGs, namely to Goal 8 to "achieve full and productive employment and decent work for all women and men [...] including for persons with disabilities" (United Nations, 2015a), to Goal 10 to "reduce inequality [....] by empowering and promoting the social, economic and political inclusion of all, including persons with disabilities (ref)" and to Goal 17 to "increase significantly the availability of high-quality, timely and reliable data disaggregated by [...] disability [...] relevant in national contexts" (United Nations, 2015b).

From a corporate reporting view, the GRI framework provided the first set of guidelines and can be regarded as 'the de facto global standard' for sustainability reporting by the leading global companies (Hahn \& Lülfs, 2014). However, companies often find the GRI frameworks too time-consuming with too much emphasis on accounting indicators (Knudsen, 2006), which is also true for the D\&A aspect, as the GRI framework (ref) also provides extensive reporting guidelines on six categories with 31 exhaustive and details indicators. In particular, the GRI framework includes 'Organizational governance and values' (with five core performance indicators), 'Embedding respect'(with seven core performance indicators), 'Employment and decent work' (with five core performance indicators), 'Accessibility' (with six core performance indicators), 'Business relationships' (with four core performance indicators) and 'Community' (with four core performance indicators) in their reporting guidelines. Given the effort to complete these indicators, the GRI guidelines can be seen as a framework that promotes a 'managerialist' approach (i.e. a box ticking exercise) to sustainability rather than an informed approach (i.e. being a sustainable member of society) and is often considered too difficult and too complicated to complete (Dumay, Guthrie, \& Farneti, 2010).

In response, we propose a new simplified Disability \& Accessibility Management Framework (DAMF) that provides a conceptual foundation to report corporate D\&A initiatives and activities under the sustainability umbrella (see Fig. 1). Although the GRI and the SDGs mention mainly disability in their goals, these statements are strongly related to accessibility, but it is important to distinguish between those elements, in particular from corporate viewpoint. While disability can be regarded as an umbrella term that covers impairment and activity limitations, disability from a corporate view could be viewed as a specialized area of human resources, to support efforts by employers to better integrate and retain workers with 
disabilities (Disabled World, 2019). Thus, disability in a company context is related to the workforce, i.e. to the persons employed.

In contrast, accessibility can be defined as the 'ability to access' environments and products \& services, for people with disabilities. As such, from a corporate viewpoint, accessibility is related to a) the workplace, i.e. representing a disability-inclusive workplace that ensures both 'direct access' (i.e. unassisted) and 'indirect access' meaning compatibility with a person's assistive technology (for example, computer screen readers), and b) the products \& services of a company, i.e. using universal design to create products that are usable by people with the widest possible range of abilities and operating within the widest possible range of situations (such as a website that can be navigated effectively by people with visual impairments).

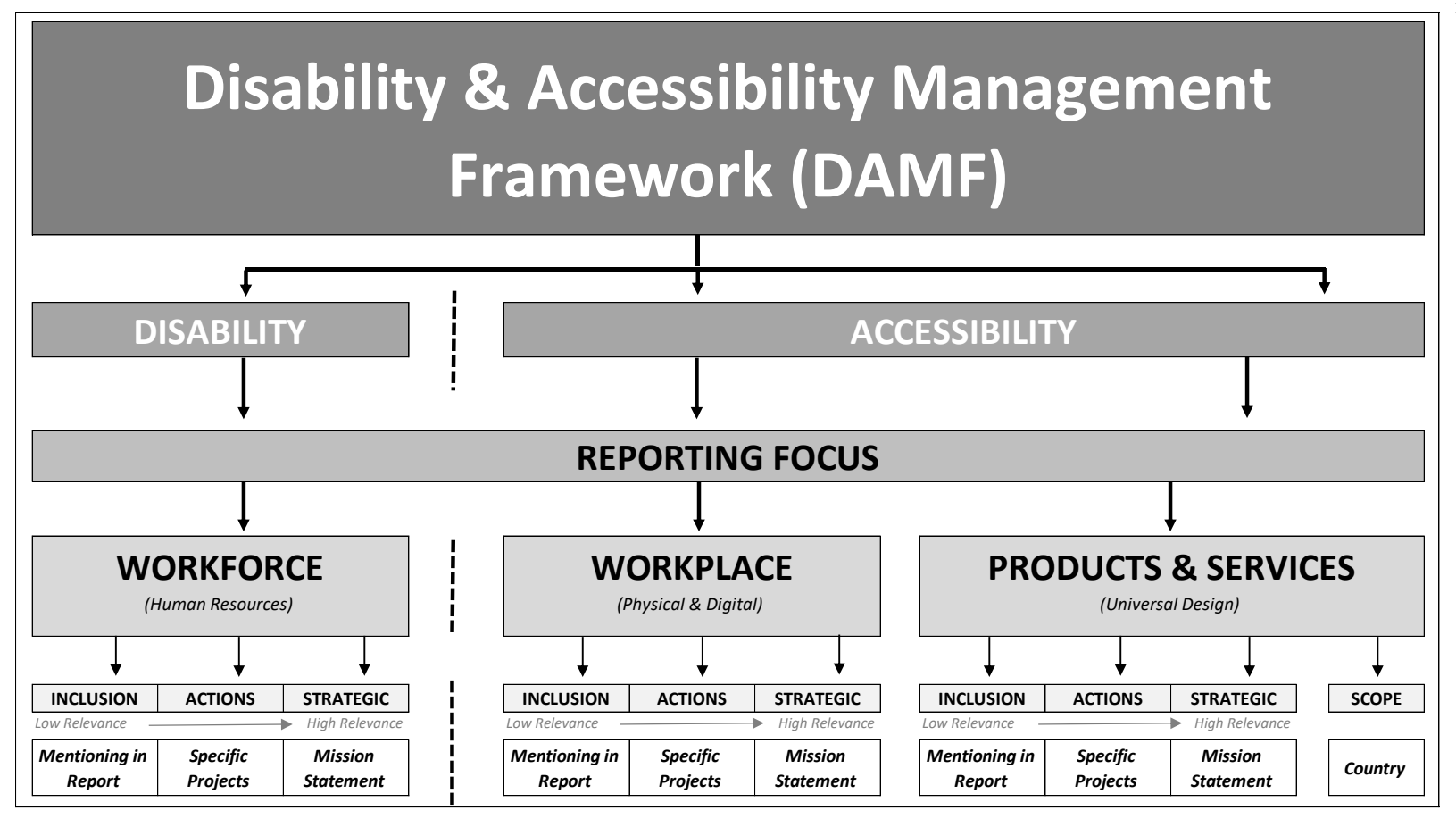

Fig. 1: The Disability and Accessibility Framework (DAMF)

From a social sustainability reporting viewpoint, we argue that these three key pillars consisting of 'Workforce', 'Workplace' and 'Products \& Services' not only provide a simplified overview about the importance of the role of D\&A in corporate sustainability reporting, but also build a conceptual foundation to categorize the corporate D\&A initiatives and activities. In order to understand the degree of a company's involvement in D\&A, each pillar distinguishes between three reporting elements from low relevance to high relevance, ranging from 'Inclusion' over 'Actions' to 'Strategic' (see Fig. 1).

This can also be seen as a response or an offer to the corporate world to address the lack of a cohesive strategy to generate the data needed in a consistent and methodological accepted way for D\&A reporting. The next section presents the methodology behind the data collection and explains in detail the factors and sub-points that are used to analyze the extent of D\&A reporting in corporate sustainability reporting.

\section{Methodology}


To address the research aim of examining the aspects of D\&A which are included in corporate sustainability reporting, the D\&A categories as identified in the framework were analysed. In particular, we adopted an interpretative content analysis approach of the statements and declarations of the corporate sustainability reports from the 50 largest companies in Europe according to Euro Stoxx in June 2019. Euro Stoxx is an index of Eurozone stocks representing fifty of the largest and most liquid blue-chip stocks (Euro Stoxx, 2019). Euro Stoxx were chosen because the information provided serves as an underlying source for many strategy indices the index accurately represents the performance of only the biggest and most liquid stocks. Consequently, the companies listed in Euro Stoxx 50 provide an ideal example to assess the extent of D\&A reporting.

Adopting interpretative content analysis (see e.g. Baxter, 1991) provides in-depth insights into the reporting behavior of the companies and enables a discussion of the D\&A activities. It is therefore not a quantitative comparison of disability activities, goals and/or achievements. Rather, interpretative analysis captures meaning by disaggregating narrative into its constituent parts and then describing the contents of each disaggregated component (e.g., Cormier \& Gordon, 2001; Milne, Tregidga, \& Walton, 2003). The capture of the actual content of narrative is important when researchers are interested in understanding disclosure practice (e.g., Hammond \& Miles, 2004). Thus interpretative studies aim to gain a greater understanding of what is communicated and how meaning is understood (e.g., Laine, 2005). They are therefore concerned with the quality, richness or qualitative character of the narrative. In other words, interpretative analysis is the contextualization of communication, and seeks to reveal the meanings and motivations behind statements in corporate reporting and in this case, how much importance and to what extent D\&A activities are represented in the corporate sustainability reporting of the largest 50 companies in Europe.

The majority of the companies publishes corporate sustainability reports on an annual basis (although some companies call it 'corporate social reporting', 'corporate social responsibility' or 'corporate citizenship' reports), and the latest ones were chosen. In particular, this study focuses on reports from 2018, and where no 2018 report was available, a 2017 report was chosen.

To assess to what extent DA\& activities were represented in the corporate reports, we followed the structure of the DMAF's three categories: (1) disability - workforce; (2) accessibility - workplace; and (3) accessibility - products \& services (see Fig. 1). To distinguish the relevance of the D\&A activities, each pillar is further split into elements from low relevance to high relevance, ranging from 'Inclusion' (indicating low relevance), 'Actions' (indicating medium relevance) and 'Strategic' (indicating high relevance).

The first category investigates the disability activities in corporate reporting - that is, how the workforce of disabled people was reported and what activities and initiatives were described by employers to better integrate and retain workers with disabilities. Strongly related to human resources management, disability activities may include the proportion of disabled people per organization or country and what training or educational programs are provided to disabled and non-disabled employees. Apart from that, we also assessed if the programs or activities had a strategic, i.e. a long-term intention or commitment. Consequently, and in line with our approach to distinguish the relevance of activities, we divided the disability category into 'Inclusion' (e.g. how many disabled people are reported), Actions (e.g. programs that 
train or educate employees in the context of disability) and Strategic (e.g. a long-term commitment of the company to disabled people).

The second category examines the physical and digital accessibility activities in corporate reporting - that is, how the workplace accessibility for disabled people is reported and what activities and initiatives are described to ensures both 'direct access' (i.e. unassisted) and 'indirect access' (assistive technology), thus representing disability-inclusive workplace. Physical and digital accessibility activities may include the resources needed at the workplace for disabled people (e.g. elevators, ramps, etc) or assistive technology (e.g. computer screen readers). Again, we also assessed if the programs or activities have a strategic, i.e. a long-term intention or commitment. As such, we divided the physical and digital accessibility category into 'Inclusion' (e.g. is accessibility in the context of disabled people mentioned), 'Actions' (e.g. programs that enhance the accessibility at the workplace) and 'Strategic' (e.g. a longterm commitment of the company to enhance accessibility).

The third category deals with the universal design of accessibility activities in corporate reporting - that is, how products \& services in the context of accessibility is reported and what corporate products $\&$ services are created that are used by disabled people inside and outside the company. Universal design accessibility activities include products \& services with the widest possible range of abilities and operating within the widest possible range of situations (such as a website that can be navigated effectively by people with visual impairments). Again, we also assess if the programs or activities have a strategic, i.e. a longterm intention or commitment. To distinguish between these activities, we again divided the universal design accessibility category into 'Inclusion' (e.g. mentioning of accessible products $\&$ services for disabled people), 'Actions' (e.g. programs that enhance the accessibility of products \& services) and 'Strategic' (e.g. a long-term commitment of the company to enhance the accessibility of products $\&$ services).

\section{Discussion of Results}

In this section, we present the results from our analysis of the D\&A activities of the 50 largest companies in Europe according to their corporate sustainability reports. The analysis is based on the newly developed DAMF framework and the associated key pillars 'Workforce', 'Workplace' and 'Products \& Services'. 'Inclusion' activities reflect the existence of D\&A in a respective corporate report, i.e. it shows that D\&A are part of sustainability activities and are incorporated in the reporting structure. 'Actions' refers to activities that are related to specific D\&A projects (e.g. education, awareness, infrastructure), while 'Strategic' activities reflect not only a long-term approach, but the reporting emphasizes D\&A activities with a mission statement.

Distinguishing between D\&A activities, it could be observed that the majority of the companies focus on the disability, thus from the workforce perspective, 74 per cent ( 37 out 50 reports) mentioned disability in their reports. In contrast, discussing or mentioning products \& services with regard to D\&A seems not be a focus of companies so far, with only 8 per cent (4 out of 50) mentioning specific D\&A products \& services. From a workplace perspective, only 10 per cent (5 out of 50) reports discuss or mention D\&A activities, thus leaving disability and workforce issue as the most prominent driver of D\&A reporting in European companies. 
The details of the results including to what extent each element was represented in the corporate reports of the 50 largest companies in Europe is discussed below.

\subsection{Disability - Workforce}

From a workforce or human resources viewpoint, the majority of companies, representing 74 per cent (37 out of 50), include 'Disability' and mention disabled persons in their corporate sustainability reports, mainly under the 'diversity and inclusion' section. The statements range from focusing "on employees who experience disability" (ING, 2018, p. 38), "advance inclusion of employees and customers with disabilities" (Allianz, 2018, p. 65), to "integrating people with disabilities into our organization" (EON, 2018, p. 71). Within these reports, 36 per cent (18 out 50) report the number of disabled people working in the organization.

With regard to actions for disabled people, 34 per cent (17 out of 50) reported projects that specifically dealt with disabled people in the organization. For example, some had "signed collective agreements or taken measures to support people with disabilities (recruitment, accessibility, training, awareness-raising measures)" (BNP Paribas, 2017, p. 75) or "working on part-time contracts in the bakery and stationary departments" for disabled people (Auchan, 2017, p. 16). Some were "cooperating with the severely handicapped persons' representative to put together a plan of action for taking on disabled trainees" (Daimler, 2018, p. 99) or working together with other disability consultancies "to increase our understanding of the needs of disabled candidates in our application and hiring processes" (BP, 2018, p. 57). Some companies also referred to the SDG goals in their reports or highlight their engagement with the International Labour Organization (ILO).

From a strategic perspective, only one company, Auchan seems to have integrated disability as an integral part of the company's mission. The reporting about people disabilities stretched over two pages and list specific educational projects in several countries and cooperation with non-government organizations (NGOs) for further inclusion.

Overall, although almost three quarters of the companies included and mentioned them in their respective corporate reports, it seems that disability reporting and activities play rather a minor role in corporate sustainability reporting. D\&A activities were mostly mentioned among other activities in the 'diversity and inclusion' section, and thus were only mentioned briefly without any extensive description or analysis. From a pure 'action' perspective, more than one third of the companies were involved in specific projects with NGOs or consultancies that were supporting disabled people or mention the SDG goals in their reporting. Strategically, all but one company did not seem to have a long-term commitment or a mission statement with regard to disability in the workforce, thus amplifying the conclusion that disability lacked importance in corporate sustainability reporting.

\subsection{Accessibility - Workplace}

In contrast to reporting about disability and a disabled workforce, accessibility at workplace seems to play a smaller role in the corporate reporting of the 50 largest European companies. Only 10 per cent ( 5 out 50) of the companies included or mentioned workplace-accessibility activities in their corporate reports. The statements range from fostering "a culture of inclusion" and ensuring "our workplaces are accessible for people with disabilities (Deutsche 
Telekom, 2017, p. 18) to paying "particular attention to the integration of employees with disabilities" (Volkswagen, 2018, p. 70). The remaining companies, representing 90 per cent (45 out of 50), seemed to neglect accessibility at the workplace in their corporate reports.

With regard to actions for disabled people, the same 10 per cent (5 out of 50) reported projects that specifically dealt with accessibility in the workplace. These projects are often related to specific action plans, for example, Deutsche Telekom has introduced "Living Diversity - Inclusion@DT" action plan (p. 122), while Siemens introduced

"Ability@Siemens" (p. 18), which strives to a create a barriers-free work environment, e.g. the use of elevators, having subtitles underneath videos, or providing transcriptions that can be read out loud when using a computer. Other companies set up specifically workshops and workstations for people with disabilities (Volkswagen, 2018), provide wheelchair access at call centres (Munich RE, 2018) or offer training in sign language to all employees (Auchan, 2017).

From a strategic perspective, it seems that Deutsche Telekom as well as Siemens with their statements and action plans ("Living Diversity - Inclusion@DT” and "Ability@Siemens", respectively) could be regarded as a long-term commitment, although a specific mission statement could not be identified. Moreover, Auchan seems also to have accessibility at the workplace integrated in their reports, thus reflecting a strategic approach. For example, to heighten customer awareness of employees with disabilities, the presence of cash register attendants who are deaf or hard of hearing is indicated by specific signage at the registers.

Overall, only one in ten companies include activities regarding physical and digital accessibility in their corporate sustainability reporting. If accessibility in the context of physical and digital access was mentioned, the reports often refer to general descriptions and terms without mentioning specific actions or showing any inclusion examples. However, the same ten per cent that mention physical and digital accessibility activities in their reports, seem to have also developed specific programs and actions that specifically deal with accessibility in the workplace. Six per cent of the companies even have developed types of specific inclusion or accessibility statements and slogans to guide and support workplace actions.

D\&A activities were mostly mentioned among other activities in the 'diversity and inclusion' section, thus only mentioned briefly without any extensive description or analysis. From a pure 'action' perspective, more than one third of the companies were involved in specific projects with NGOs or consultancies to support disabled people or mention the SDG goals in their reporting. Strategically, all but one company did not seem to have a long-term commitment or a mission statement with regard to disabled workforce, thus supporting the conclusion that accessibility is rather neglected in corporate sustainability reporting.

\subsection{Accessibility - Products \& Services}

Similar to the accessibility at the workplace, the accessibility of products \& services seemed to also be a neglected issue in the corporate reporting of the 50 largest European companies. Again, only 10 per cent ( 5 out of 50) of the companies included or mentioned products \& services-accessibility activities in their corporate reports. The statements ranged from "the development of products and services adapted to the needs of people with disabilities, turning innovative and disruptive ideas into reality“ (Telefonica, 2018, p. 41) to supporting 
"individuals with special mobility needs. For an individual with a disability, accessible mobility can offer an increased level of independence" (Fiat Chrysler Automobiles, 2018, p. 87). The remaining companies, representing 90 per cent (45 out of 50), seemed to neglect accessibility for the products $\&$ services in their corporate reports.

With regard to actions for products \& services, only 6 per cent ( 3 out of 50) reported projects that specifically dealt with accessibility for products $\&$ services. For example, Telefonica (2018) worked closely with leading disability associations to develop products \& services, while Fiat (2018) provided "assistance toward the purchase of appropriate customizable adaptive equipment" (p. 87) for disabled customers, including assistance with a range of administrative, legal and technical issues, fitness-to-drive screening assessments, and information on test drives.

From a strategic perspective, it seemed that only Fiat and Telefonica had a long-term commitment to accessible products and services. Telefonica, for example, had introduced the concept of 'Design for All', incorporating accessibility in their processes, products and services from design stage, where training and awareness raising activities for employees were organized, in particular, for the developers of Telefonica's channels and solutions.

Overall, similarly to the previous section, only one in ten companies include activities regarding universal design accessibility in their corporate sustainability reporting. If accessibility in the context of universal design is mentioned, the statements in the reports range from rather general descriptions and terms without mentioning specific actions to concrete implementing of ideas. As such, based on their corporate sustainability reports, it can be concluded that six per cent of the companies had developed specific universal design products and services that are custom-tailored for disabled people. Four per cent of the companies had even developed specific inclusion or accessibility statements represent the company commitment to creating accessible products and services.

\section{Conclusion}

The results provide interesting insights into the D\&A reporting of the 50 largest companies in Europe in 2017 and 2018. Our examination in corporate sustainability revealed substantial differences between the companies' approach towards D\&A categories and the reporting elements. The overall degree of D\&A reporting can be considered as rather low. Although almost three quarters of the companies included and mentioned disability in their respective corporate reports, it seems that disability reporting and activities play rather a minor role in corporate sustainability reporting. Disability activities were mostly mentioned among other activities in the 'diversity and inclusion' section, thus often only mentioned briefly without any extensive description or analysis. From a pure 'action' perspective, more than one third of the companies reported being involved in specific projects with NGOs or consultancies that support disabled people or mention the SDG goals in their reporting. Strategically, all but one company did not seem to have a long-term commitment or a mission statement with regard to disabled workers, thus supporting the conclusion that disability lacks importance in corporate sustainability reporting.

From a physical and digital accessibility perspective only one in ten companies included activities in their corporate sustainability reporting. When accessibility in the context of physical and digital access was mentioned, the reports often referred to general descriptions 
and terms without mentioning specific actions or showing any inclusion examples. However, the same ten per cent that mentioned physical and digital accessibility activities in their reports, seemed to have also developed specific programs and actions that specifically deal with accessibility in the workplace. Three companies even had developed types of specific inclusion or accessibility statements and slogans to guide and support workplace actions.

Only one in ten companies included activities regarding universal design accessibility in their corporate sustainability reporting. If accessibility in the context of universal design was mentioned, the statements in the reports ranged from rather general descriptions and terms without mentioning specific actions to concrete implementing of ideas. As such, six per cent of the companies had developed specific universal design products and services customtailored for disabled people. Four per cent of the companies had even developed types of specific inclusion or accessibility statements to represent the company's commitment to creating accessible products and services.

The results of the analysis must be interpreted in the light of its limitations. The sample size is quite small withy only 50 reports, limiting the generalizability of the results. However, we could observe a decline in reporting in correlation with market size, so we do not expect a more extensive D\&A reporting of smaller companies to yield additional information. Like all approaches adopting interpretative content analysis, the data analysis is inherently narrative, as it relies on reported information as reflective of corporate actions and intent. In addition, the analysis comprised only corporate sustainability reports, and it may be the case that different or more extensive disclosure is made elsewhere. We invite future research to expand the research either in another country setting or using a more comprehensive data set. Interestingly, in the absence of any regulatory requirements, this relatively new GRI framework from 2015 on disability seems to be hardly used in current practice. As such, we conclude that D\&A reporting is still in its infancy, and as organizations are increasingly under pressure to incorporate the social side of sustainability, our framework may help to drive a simplified D\&A reporting approach and provide a theoretical foundation to assess the extent of D\&A activities.

Acknowledgements

None.

\section{Financial Support}

This research received no specific grant from any funding agency, commercial, or not-forprofit sectors.

\section{Conflicts of Interest}

None.

\section{References}


Allianz. (2018). Allianz Group Sustainability Report. Retrieved from: https://www.allianz.com/en/sustainability/strategy-governance/sustainabilityreport.html

Amla, I. (2008). Managing and sustaining a world of workplace diversity: the Accenture experience. Strategic HR Review, 7(5), 11-16.

Auchan. (2017). CSR Section of the 2017 Management Report. Retrieved from: https://www.auchanholding.com/uploads/files/modules/articles/1504191195_59a822db64cce.pdf

Babiak, K., \& Trendafilova, S. (2011). CSR and environmental responsibility: Motives and pressures to adopt green management practices. Corporate Social Responsibility and Environmental Management, 18(1), 11-24.

Baumgartner, R. J. (2014). Managing corporate sustainability and CSR: A conceptual framework combining values, strategies and instruments contributing to sustainable development. Corporate Social Responsibility and Environmental Management, 21(5), 258-271.

Baxter, L. A. (1991). Content analysis. In B. M. Montgomery \& S. Duck (Eds.), Studying interpersonal interactions (pp. 254-293). New York, NY: The Guilford Press.

BNP Paribas. (2017). Report on activity and corporate responsibility. Retrieved from: http://report-activity-corporate-responsibility-2017.bnpparibas/

BP. (2018). Sustainability Report. Retrieved from: https://www.bp.com/content/dam/bp/businesssites/en/global/corporate/pdfs/sustainability/group-reports/bp-sustainability-report2018.pdf

Breitbarth, T., \& Herold, D. M. (2018). Closing the academia-practice gap in corporate sustainability management research: Challenges and bridges. Journal of Environmental Sustainability, 6(1), 4.

Brundtland, G. H. (1987). Our common future: Report of the World Commission on Environment and Development (Vol. 383). Oxford: Oxford University Press.

Cordero, J., de Zúñiga, T. O., \& Rueda, M. (2014). Disability and corporate social responsibility reporting: An analysis comparing reporting practices of 40 selected multinational enterprises. Geneva: International Labour Organization.

Cormier, D., \& Gordon, I. M. (2001). An examination of social and environmental reporting strategies. Accounting, Auditing \& Accountability Journal, 14(5), 587-617.

Cuthill, M. (2010). Strengthening the 'social'in sustainable development: Developing a conceptual framework for social sustainability in a rapid urban growth region in Australia. Sustainable Development, 18(6), 362-373.

Daimler. (2018). Sustainability Report. Retrieved from: https://www.daimler.com/documents/sustainability/other/daimlernachhaltigkeitsbericht-2018-en.pdf

Dempsey, N., Bramley, G., Power, S., \& Brown, C. (2011). The social dimension of sustainable development: Defining urban social sustainability. Sustainable Development, 19(5), 289-300.

Deutsche Telekom. (2017). Corporate Responsibility Report. Retrieved from: https://www.crreport.telekom.com/site18/sites/default/files/pdf/cr_en_2017_dt_final.pdf

Disabled World. (2019). Defining Disabled and Disability. Retrieved from: https://www.disabled-world.com/disability/accessibility/

Dumay, J., Guthrie, J., \& Farneti, F. (2010). GRI sustainability reporting guidelines for public and third sector organizations: A critical review. Public Management Review, 12(4), 531-548. Retrieved from https://www.scopus.com/inward/record.uri?eid=2-s2.077954697512\&partnerID=40\&md5=929f0d5e352ff53a9dd1959abe747359. doi:10.1080/14719037.2010.496266 
Eizenberg, E., \& Jabareen, Y. (2017). Social sustainability: A new conceptual framework. Sustainability, 9(1), 68.

EON. (2018). Sustainability Report. Retrieved from:

https://www.eon.com/content/dam/eon/eon-com/Documents/en/sustainabilityreport/EON_Sustainability_Report_2018.pdf

Euro Stoxx. (2019). Euro Stoxx 50. Retrieved from https://www.stoxx.com/indexdetails?symbol=SX5E

Fiat Chrysler Automobiles. (2018). Sustainability Report. Retrieved from: https://www.fcagroup.com/en-

US/investors/financial_information_reports/sustainability_reports/sustainability_repor ts/FCA_2018_Sustainability_Report.pdf

Gray, R. (2006). Social, environmental and sustainability reporting and organisational value creation? Accounting, Auditing \& Accountability Journal, 19(6), 793-819.

Griessler, E., \& Littig, B. (2005). Social sustainability: a catchword between political pragmatism and social theory. International Journal for Sustainable Development, $8(1 / 2), 65-79$.

Hahn, R., \& Lülfs, R. (2014). Legitimizing negative aspects in GRI-oriented sustainability reporting: A qualitative analysis of corporate disclosure strategies. Journal of Business Ethics, 123(3), 401-420.

Hammond, K., \& Miles, S. (2004). Assessing quality assessment of corporate social reporting: UK perspectives. Accounting Forum, 28(1), 61-79. Retrieved from https://www.scopus.com/inward/record.uri?eid=2-s2.023744509378\&partnerID=40\&md5=bdea4511f280503f9d01441f6832231a.

Herold, D. M., Farr-Wharton, B., Lee, K. H., \& Groschopf, W. (2018). The interaction between institutional and stakeholder pressures: Advancing a framework for categorising carbon disclosure strategies. Business Strategy \& Development, 2(2), 77 90.

Herold, D. M., \& Lee, K.-H. (2019). The influence of internal and external pressures on carbon management practices and disclosure strategies. Australasian Journal of Environmental Management, 26(1), 63-81.

Herremans, I. M., Nazari, J. A., \& Mahmoudian, F. (2016). Stakeholder relationships, engagement, and sustainability reporting. Journal of Business Ethics, 138(3), 417-435.

ING. (2018). Human Rights. Retrieved from: https://www.ing.com/web/file?uuid=395f8c43e9b2-4691-b5c1-024819670a09\&owner=b03bc017-e0db-4b5d-abbf003b12934429\&contentid $=45372$

Knudsen, J. S. (2006). The Global Reporting Initiative in Denmark: Emperor's New Clothes or Useful Reporting Tool? In Corporate Social Responsibility (pp. 129-139): Springer.

Kolk, A. (2003). Trends in sustainability reporting by the Fortune Global 250. Business Strategy and the Environment, 12(5), 279-291.

KPMG. (2017). The road ahead - The KPMG Survey of Corporate Responsibility Reporting Retrieved from: https://assets.kpmg/content/dam/kpmg/xx/pdf/2017/10/kpmg-surveyof-corporate-responsibility-reporting-2017.pdf

Kunz, J. (2006). Social sustainability and community involvement in urban planning. Retrieved from:

Laine, M. (2005). Meanings of the term 'sustainable development' in Finnish corporate disclosures. Accounting Forum, 29(4), 395-413.

Lee, K.-H., Herold, D. M., \& Yu, A.-L. (2016). Small and Medium Enterprises and Corporate Social Responsibility Practice: A Swedish Perspective. Corporate Social Responsibility and Environmental Management, 23(2), 88-99. 
Maas, K., Schaltegger, S., \& Crutzen, N. (2016). Integrating corporate sustainability assessment, management accounting, control, and reporting. Journal of Cleaner Production, 136, 237-248.

McKenzie, S. (2004). Social sustainability: towards some definitions. Retrieved from:

Milne, M. J., \& Gray, R. (2013). W(h)ither Ecology? The Triple Bottom Line, the Global Reporting Initiative, and Corporate Sustainability Reporting. Journal of Business Ethics, 118(1), 13-29. Retrieved from https://www.scopus.com/inward/record.uri?eid=2-s2.084888133084\&partnerID=40\&md5=9371db57f1656058c132f27d5a661801. doi:10.1007/s10551-012-1543-8

Milne, M. J., Tregidga, H., \& Walton, S. (2003). The triple bottom line: Benchmarking New Zealand's early reporters. University of Auckland Business Review, 5(2), 36-50.

Missimer, M. (2013). The social dimension of strategic sustainable development. (Doctoral Dissertation), Blekinge Institute of Technology, Karlskrona, Sweden.

Missimer, M., Robèrt, K.-H., \& Broman, G. (2017). A strategic approach to social sustainability-Part 1: exploring the social system. Journal of Cleaner Production, 140, $32-41$.

Munich RE. (2018). Corporate Responsibility Report. Retrieved from: https://www.munichre.com/content/dam/munichre/global/contentpieces/documents/MunichRe-CR-Report2018.pdf/_jcr_content/renditions/original./MunichRe-CR-Report-2018.pdf

Nations, U. (2016). Convention on the Rights of Persons with Disabilities. Retrieved from: https://www.un.org/disabilities/documents/convention/convoptprot-e.pdf

Telefonica. (2018). Consolidated Management Report 2018. Retrieved from: https://www.telefonica.com/web/responsible-business/report-2018

United Nations. (2015a). The Millenium Development Goals Report. Retrieved from: https://www.un.org/millenniumgoals/2015_MDG_Report/pdf/MDG\%202015\%20rev $\% 20($ July\%201).pdf

United Nations. (2015b). Transforming Our World: The 2030 Agenda For Sustainable Development. Retrieved from: https://sustainabledevelopment.un.org/content/documents/21252030\%20Agenda\%20f or\%20Sustainable\%20Development\%20web.pdf

Vallance, S., Perkins, H. C., \& Dixon, J. E. (2011). What is social sustainability? A clarification of concepts. Geoforum, 42(3), 342-348.

Van Marrewijk, M. (2003). Concepts and definitions of CSR and corporate sustainability: Between agency and communion. Journal of Business Ethics, 44(2-3), 95-105.

Volkswagen. (2018). Sustainability Report. Retrieved from: https://www.volkswagenag.com/presence/nachhaltigkeit/documents/sustainabilityreport/2018/Nonfinancial_Report_2018_e.pdf

WHO. (2011). World report on disability Retrieved from: https://www.who.int/disabilities/world_report/2011/report.pdf

Wolbring, G., Mackay, R., Rybchinski, T., \& Noga, J. (2013). Disabled people and the post2015 development goal agenda through a disability studies lens. Sustainability, 5(10), $4152-4182$.

Wolbring, G., \& Rybchinski, T. (2013). Social sustainability and its indicators through a disability studies and an ability studies lens. Sustainability, 5(11), 4889-4907. 